\title{
Housing Tenure and Informational Asymmetries
}

\author{
Herman Donner ${ }^{1}$ and Fredrik Kopsch ${ }^{2}$
}

Abstract:

The paradigm shift of focus from rental apartments to owner occupied units on the Swedish property market has led to a substantial number of rental apartments being converted to cooperative apartments. Such conversions typically are done at prices far below market value. This provides a setting with strong financial incentives for tenants involved in such a conversion to take advantage of their informational advantage regarding the financial management of a cooperative, as compared to less informed neighbors and buyers on the general market. This setting also provides a reliable way of estimating the persistence and effects of such an informational asymmetry through nearly 200,000 apartment transactions in Stockholm, Sweden during the period of 2005 to mid-2014. We find strong support towards a behavior concurrent with moral hazard; as such insiders mismanage the cooperatives by setting monthly fees artificially low in order to increase the probability of a conversion as well as apartment values. Lastly, market participants seem to discount this informational asymmetry as recently converted apartments sell at lower prices.

JEL-classifications: D80; D82; R30; R31

Keywords: Informational Asymmetries, Real Estate, Housing Tenure,

1Department of Real Estate and Construction Management / Division of Building and Real Estate Economics KTH Royal Institute of Technology, Stockholm, Sweden

Drottning Kristinas Väg 30, 100 44, Stockholm, Sweden

Corresponding author at: herman.donner@abe.kth.se

$+46(0) 708257272$

${ }^{2}$ Departement of Technology and Society / Division of Real Estate Science.

Lund University, Lund, Sweden

Ole Römers väg 3D, 223 63, Lund, Sweden 


\section{Introduction}

Real estate is a fairly complex asset of which transactions require a great deal of effort. As a consequence, real estate is also less liquid than other assets - as the sellers and buyers have greater difficulty finding each other, as well as coming to an agreement on price. Given the heterogeneous nature of real estate, it is to be expected that real estate prices are associated with a great deal of "noise" as compared to homogenous financial assets such as stocks and bonds. The nature of real estate is therefore likely to produce informational asymmetries that in turn cause market inefficiencies. Such inefficiencies due to different levels of information regarding some heterogeneous asset amongst market participants has been examined on a magnitude of markets by researchers, such as health insurance (Altman et al., 1998; Handel, 2013), labor markets (Campbell and Kamlani, 1997; Greenwald, 1986), and the used car market (Genesove, 1993; Porter and Sattler, 1999). Studies having examined informational asymmetries between participants on the real estate market are provided by Garmaise and Moskowitz (2004), Levitt and Syverson (2008) and Kurlat and Stroebel (2015).

This paper adds a new dimension to the effects of informational asymmetries on the real estate market by analysis of the paradigm shift of the Swedish apartment market, with a substantial increase in rental units being converted into owner-occupied apartments since the late 1990s and onwards. As these apartments are owned in cooperative form, there are ample opportunities for individuals that are involved in the conversion process to take advantage of their higher level of knowledge regarding the management of the cooperative, this as compared to less informed neighbors and buyers of such converted apartments. As conversions typically are done at prices far below market value, this also provides a setting with strong financial incentives to take advantage of such an informational asymmetry. The main hypothesis is that those involved in conversions have an incentive to set monthly fees of newly converted apartments below sustainable levels given by the costs of running a housing cooperative. When comparing the monthly costs of being a tenant as compared to owning, lower monthly fees will make the prospect of buying more attractive. Consequently, if tenants and buyers are uninformed regarding the running of the cooperative, financial mismanagement of the cooperative through "artificially" low monthly fees will increase the 
probability of a conversion as well as increase apartment values. Through transaction data with property and cooperative characteristics, an effective way of measuring the effects of such informational asymmetry is provided.

As most would expect, sellers of real estate typically have greater knowledge regarding property condition as well as locational characteristics as compared to buyers. Buyers of commercial real estate have been found to resolve this issue by buying properties with long income histories in addition to avoiding buying from informed professional sellers (Garmaise and Moskowitz, 2004). Such informational asymmetries should increase with the complexity of the traded asset; real estate in liquid markets with many comparable transactions should decrease such an informational asymmetry, whilst real estate in illiquid markets or those with few or no comparable transactions will pose a greater challenge for buyers to evaluate. Consequently, as a consequence of diverging finances and management of housing cooperatives, apartments in cooperative form adds significant complexity to the real estate asset, as compared to condominiums. Further difficulty is added by the lack of transaction history of apartments having been converted from rentals to owner occupied.

The remainder of this paper is structured as following: section 3 provides a brief summary of previous research, section 4 describes the theoretical framework and the hypotheses, and section 5 covers the methodology and results. Section 6 concludes. 
2. Review of previous research findings

The issue at hand, of informed decisions makers within housing cooperatives that potentially exploit their informational advantage as compared to outsiders, will if true lead to behavior concurrent with moral hazard. The problems that arises when some market participants are more informed than others is often illustrated with the used car market as an example, as in the seminal paper by Akerlof (1970) in which informational asymmetries lead to an adverse selection of lemons amongst used cars. Difficulties of individuals above 65 years of age to acquire health insurance and employers refusing to hire minorities are additional economic outcomes that can be explained by varying levels of information amongst market participants (Akerlof, 1970). Subsequent studies provide empirical tests for informational asymmetries of a wide variety of markets, with Genesove (1993) and Porter and Sattler (1999) examining the abovementioned market for used cars. Examples of studies of other markets are provided by Chiappori and Salanie (2000) and Finkelstein and Poterba (2002), which are studies of the insurance markets, as well as by Landers et al. (1996) and Campbell and Kamlani (1997) whom tested labor markets.

This study explores a dimension of sellers of real estate that are at an informational advantage as compared potential buyers. This issue has received some attention by previous research, with Garmaise and Moskowitz (2004) having tested the effects of informational asymmetries on commercial real estate markets, finding strong evidence of market participants making informational considerations by avoiding buying from informed professional sellers and preferring properties with long income histories. That more informed sellers do tend to take advantage of their informational advantage as compared to buyers is supported by findings of Kurlat and Stroebel (2015) that examined the seller composition across neighborhoods. It is found that an increase in the fraction of informed sellers, or such sellers that have larger supply elasticity predicts subsequent house price declines. The influence that institutional settings have on the impact that informational asymmetries have on the real estate markets is examined by Chau and Choy (2011) as the price premium paid for lemons on real estate markets under diverging legal institutions is estimated, finding that properties with a hidden flaw being overpriced by $6.7 \%$ when sellers 
are subject to stricter obligations to inform buyers. In contrast, a setting in which a greater share of responsibility is to be put on the buyer, the price premium is found to be $9.9 \%$.

Conversions in which a limited number of insiders set cooperative monthly fees corresponds to a situation in which an uninformed principal is informed by a more informed agent, such as described by Crawford and Sobel (1982) whom provided a model for which a principal will take into account distorted incentives and consequently discount the advice given by the agent. It is however unclear if the incentives for insiders to set artificially low monthly fees are known in this instance. Studies having examined the incentives in transmission of strategic information between experts and less informed decision makers can be seen to be related to this issue (Krishna and Morgan, 2001; Levy, 2004; Taylor, 1995). A number of studies have addressed the principal-agent issue between home-sellers and real estate agents, as the percentage commission system although it aligns the interests of the seller and agent in the same direction, it does not adequately align the magnitude of the interests (Anglin and Arnott, 1991; Geltner et al., 1991). Sellers want to achieve as high price as possible whilst the agent seeks to maximize expected commission whilst minimizing time and effort. These interests might diverge as the commission on the transaction received by the agent only corresponds to a small proportion of the transaction price, and therefore provide an incentive for agents to convince clients to sell quickly rather than to maximize the achieved price. Rutherford et al. (2005) and Levitt and Syverson (2008) are studies that examine the impact of such misaligned incentives by comparing prices of properties sold when an agent was hired, with prices achieved when agents sell their own homes. The former study finds that agent-owned homes sell at a 4.5\% premium, whilst not selling faster, whilst the latter study estimated a 3.7\% premium for agent-owned homes as well as such sales being on the market for 9.5 days longer.

Another sub-market of real estate is examined by Firoozi et al. (2006), having examined tax assessments of residential property. It is found that properties owned by property tax consultants that are more informed regarding the review mechanism of such assessments are found to have somewhat lower assessed values as compared to other properties. 
3. Institutional background, the information problem and hypotheses

In Sweden, and particularly in the metropolitan areas, there has been a large shift from an emphasis on rental apartments to owner occupied apartments. The reason for this shift has been an increasing tendency for tenants to demand conversions of their rental apartments to owner-occupied apartments, and the result has been a largely diminished importance of the previously dominant rental sector (for a more in depth discussion on the transitions on the Swedish housing market see Christophers (2013) and Andersson and Turner (2014)). Conversions from rental apartments to owner-occupied units have also resulted in very large wealth re-distributions. It has not been uncommon with prices far below market value, which has provided a great incentive for conversions. Such pricing is a consequence of rental properties having substantially lower values as compared to the equivalent total value of apartments in owner occupied properties. When converted, the rental property is priced in between these valuations, therefore making a conversion lucrative for both the seller and the tenants.

The Swedish market for apartments is somewhat different in an international perspective. The tenant does not own the apartment itself (with the exception of very few pure owner-occupied apartments) but rather the right to live in the apartment given by owning a fraction of the cooperative. The ownership of the property belongs to a housing cooperative, which in-turn is owned by the tenants. The finances of the housing cooperatives vary considerably in respect to the debt carried by the housing cooperative, something that the empirical analysis illustrates. A monthly fee is paid to cover running expenses such as servicing of the debt, maintenance and contingencies for larger future renovations.

The process of conversion from rental apartments to co-op apartments demands that a supermajority $(2 / 3$ vote $)$ of the existing tenants agree to the conversion. Within this process, several levels of information asymmetries emerge, so that one party has an advantage over another. It has previously been argued that existing tenants possess greater knowledge of both the dwelling and the neighborhood (Garmaise and Moskowitz, 2004; Kurlat and Stroebel, 2015). We can expand on this line of thought and assume that knowledge also varies among existing tenants. We know there is a financial incentive to 
convert a rental apartment, if we in addition assume that existing tenants have differing knowledge of the state of the property, there is a possibility for those active in conversion to mislead other tenants in order to secure a supermajority in favor of conversion. While there may indeed exist other motives or preferences for, or against, renting or owning, the single most important factor is likely the monthly cost associated with either option. If the monthly cost does not increase much due to a conversion, the conversion should be more likely to be completed. Aside from negotiating about a transaction price, the only other way of influencing the monthly cost, post-conversion, is to set a lower monthly fee. This leads to our first hypothesis:

H1: The monthly fee is lower for recently converted apartments than the rest of the market.

The monthly fee can be lower in recently converted buildings for other reasons than strategic behavior from those who want convert, e.g. lack of knowledge from all existing tenants. A lower monthly fee leads, ceteris paribus, to a higher transaction price (as monthly costs are of interest). That is, other than facilitating the conversion, an artificially low monthly fee leads to a higher expected price, should the tenant choose to sell post-conversion. The monthly fee can be lower in recently converted apartments without being "artificially" low. If, for example, recently converted apartment buildings are in a better state of repair the market average less capital is needed for future renovations. While this may certainly be the case, a tendency exists for rental apartments to be in a greater state of disrepair as compared to owner-occupied (Shilling et al., 1991). If, on the other hand, the monthly fee is indeed "artificially" low we would expect to observe correction of the monthly fee as time passes after the conversion and more information becomes available. This leads us to our second hypothesis:

H2: The monthly fee will increase more rapidly in converted cooperatives compared to the rest of the market.

As mentioned, one likely incentive to keeping the monthly fee artificially low is to generate a higher expected transaction price if the tenant should choose to sell. Although prospective buyers cannot observe the state of the building with high precision, they can observe whether the building recently has been converted or not. On an informed market, the lower monthly fee in the converted apartments would be offset by the information that the apartment recently has been converted. This leads to our third and final hypothesis:

H3: Recently converted apartments will fetch a lower transactions price compared to the rest of the market. 


\section{Data}

Transaction data of cooperative apartments sold through realtors in the greater Stockholm region during the period of 2005 through mid-2014 has been provided by the company Valueguard that constructs property indices. This data has very high market coverage and includes variables typically used when applying hedonic pricing models. This data does however lack information regarding the housing cooperative to which each apartment belongs. Despite the relevance of cooperative finances in relation to the value of an individual apartment, information regarding the housing cooperative an apartment belongs to is typically not included in Swedish transaction data. In fact, we do not know of any data or previous study having matched individual apartment transactions with their respective housing cooperative. This lack of data is likely to exacerbate any informational asymmetry on the property market regarding cooperative finances. Matching of each transaction with its housing cooperative through address information of each apartment was done by the company Hitta Brf whom compiles information about Swedish housing cooperatives. As this data includes information about the year in which the housing cooperative bought the property, properties having been converted from rentals to owned apartments are identified by comparison with the year of construction (provided in the transaction data). A property having been bought by the housing association subsequent of the year of construction is identified as a conversion ${ }^{3}$.

After having matched each transaction with the housing cooperatives, information regarding the housing cooperative has been collected from two sources. Housing cooperative debt ${ }^{4}$ in relation to size was collected through an online tool provided by Värderingsdata, a company that provides real estate market information. The fact that debt levels only is available for one period, i.e. being the most recent information about debt levels provided, should not be much of a concern as balance sheets of housing cooperatives should be fairly stable over the time period. This as housing cooperatives have very stable cash flows over time, with income being fees from apartment owners and costs consisting of upkeep and debt service.

\footnotetext{
${ }^{3} \mathrm{~A}$ threshold of 2 years is applied, so that an association having bought the property 2 years or more years subsequent of the year of construction is identified as a conversion.

${ }^{4}$ This is the most recent information of debt provided by Värderingsdata.
} 
Information about the total taxed area of the housing cooperative and the total number of apartments has been collected through the online tool provided by Datscha, also a company that provides real estate market information.

In order to capture spatial dependency of apartment value, a precise spatial measure is needed. Each transaction was therefore matched with its post code through GIS software.

The abovementioned data represents 197,055 observations representing 6772 housing cooperatives. After having excluded observations with housing association debt exceeding two standard deviations above the mean, 187,437 observations representing 6045 housing cooperatives remain.

Table 1 below provides a summary of transaction data with subdivisions based upon characteristics of the housing cooperative in which the apartment is located. The data has been subdivided based upon the age of the housing cooperative, with recent conversions defined both as those apartments having been converted during the period of 2007 through 2010 as well as those having been converted within two years prior of the transaction. Comparable statistics of apartments having been converted further back in time is provided by the sub-groups of apartments having been converted three to four years prior to the transaction, and apartments in non-converted housing cooperatives or conversions having taken place more than five years prior to the transaction (also excluding new construction). When comparing the subgroups of apartments it should be noted that the data regarding apartments converted during the period 2007 to 2010 will cover a shorter time period as no transactions have taken place prior to the conversion.

Apartment characteristics do not deviate considerably amongst these sub-groups, noteworthy is however differences in cooperative finances. Theoretically, higher levels of cooperative debt should be associated with higher monthly fees through costs of debt service. This linkage is also found in our empirical analysis. An apartment in a more than five year old cooperative is found to be associated with a considerably lower amount of debt held by the housing cooperative, whilst still having considerably higher monthly fees. On 
average, such an apartment carries 120,754 SEK or approximately 14, 000 USD less in debt through the housing cooperative as compared to apartments located in cooperatives converted within two years of the transaction. Despite higher levels of debt, recently converted apartments have considerably lower monthly fees. These initial statistics support the notion that properties having been recently converted from rentals to owner occupied housing cooperatives have artificially low monthly fees.

Table 1 - Summary statistics of cooperative apartment transactions spanning 2005 to July 2014. (Mean values with standard deviations in parenthesis).

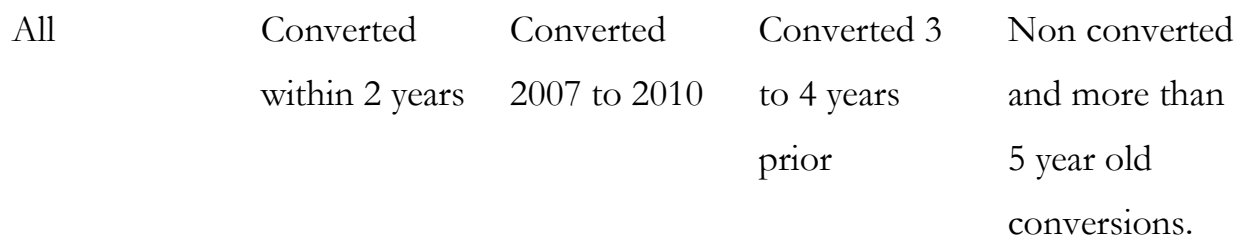

\begin{tabular}{llllll}
\hline No. Obs. & 187,437 & 14,722 & 17,848 & 11,388 & 155,633 \\
\hline Cooperative Characteristics & & & & \\
\hline Debt sqm * Living & 328907.7 & 433908.5 & 426888 & 392849.3 & 313154.2 \\
area (SEK) & $(261906.9)$ & $(229815)$ & $(224098.8)$ & $(225189.6)$ & $(265519.1)$ \\
Year of property & 1984.644 & 2008.21 & 2008.599 & 2006.271 & 1980.113 \\
purchase & $(25.01833)$ & $(2.537821)$ & $(1.096709)$ & $(3.060399)$ & $(25.11502)$ \\
\hline Apartment and Property Characteristics & & & & \\
\hline Living area (sqm) & 63.99199 & 63.12193 & 63.7732 & 61.9777 & 64.32 \\
& $(24.17757)$ & $(23.95109)$ & $(23.65184)$ & $(23.60524)$ & $(24.22484)$ \\
No. of Rooms & 2.369826 & 2.363334 & 2.412203 & 2.321303 & 2.377189 \\
& $(1.011503)$ & $(1.027227)$ & $(1.02067)$ & $(.9989611)$ & $(1.010613)$ \\
Monthly Fee (SEK) & 3343.693 & 2992.355 & 3117.217 & 3095.526 & 3403.114 \\
& $(1371.876)$ & $(1114.736)$ & $(1147.407)$ & $(1096.987)$ & $(1411.802)$ \\
Elevator & .5629945 & .5032604 & .5063873 & .5333685 & .5708751 \\
\multirow{2}{*}{ Balcony } & $(.4960171)$ & $(.5000064)$ & $(.4999732)$ & $(.4989072)$ & $(.4949528)$ \\
Floor & .1133661 & .1055563 & .0908225 & .1062522 & .1144744 \\
Age & $(.3170406)$ & $(.3072793)$ & $(.2873646)$ & $(.3081737)$ & $(.3183876)$ \\
& 2.138161 & 2.031551 & 1.951311 & 2.002942 & 2.164075 \\
& $(2.283968)$ & $(2.229467)$ & $(2.245454)$ & $(2.192093)$ & $(2.298682)$ \\
& 51.3557 & 54.47215 & 55.07945 & 57.42229 & 50.24591 \\
& $(32.55945)$ & $(25.59591)$ & $(25.6349)$ & $(24.2417)$ & $(33.75749)$ \\
\hline
\end{tabular}


5. Methodology and Results

H1: The monthly fee is lower for recently converted apartments than the rest of the market.

\section{\&}

H2: The monthly fee will increase more rapidly in converted cooperatives compared to the rest of the market.

In order to test the first hypothesis that the monthly fee is lower in housing cooperatives having recently been converted from rental apartments the monthly fees of such apartments are compared with other transactions. An initial comparison of monthly fees amongst apartments recently converted from rentals to ownership as compared to apartments with a longer history of being tenant owned supports that conversions do have lower monthly fees. As can be seen in table 1, apartments having been converted within the two preceding years of the transaction have an average monthly fee of 2992 Swedish Crowns (SEK), whilst the equivalent fee is 3403 SEK for apartments located in non-converted cooperatives or those having owned the property for more than five years. Apartments having been converted three to four years prior to the transaction have an average monthly fee of 3095 . The higher monthly fee as compared to apartments having been converted within two years of the transaction indicates that the effect a conversion has on monthly fees decreases over time. This supports the second hypothesis that monthly fees of recently converted properties will converge towards levels of comparable non-converted properties.

As monthly fees are influenced by the overall finances of the housing cooperative, correction for such influences needs to be done. Most notably would be the debt carried by the housing cooperative. Based upon the full sample of apartment transactions, the correlation between monthly fee per square meter and cooperative debt per square meter is 0.47 , meaning that for each crown in debt the housing association carries, the monthly fees increases by almost 0.5 crowns. This correlation supports the importance of cooperative debt in relation to monthly fees. Figures 2 through 5 provide kernel density estimates of monthly fees and debt levels for newly converted apartments as compared to those in older housing cooperatives. Using both a fixed measure of a conversion (converted during 2007 to 2010) or a rolling 
estimate (converted within the two years that precede the transaction), it can be seen that newly converted properties carries considerably higher levels of debt (figures 3 and 5). This is expected as property values have increased and that these cooperatives have recently bought their properties. However, given this we would expect apartments having recently been converted to have higher monthly fees, ceteris paribus. That monthly fees tend to be lower in recently converted properties (as seen in figures 2 and 4) despite these higher levels of debt strongly supports that converted housing cooperatives set monthly fees at unsustainably low levels in order to take advantage of an informational advantage. Noteworthy is that recently converted apartments are associated with considerably higher levels of debt as well as lower monthly fees regardless if a fixed measure is used such as apartments having been converted during 2007 to 2010 or if using a rolling measure such as apartments having been converted within two years prior to a transaction.

It should be noted that the interior condition of apartments are the responsibility of the individual owner, whilst overall property condition outside of the individual apartments are the responsibility of the housing cooperative. Although our data lacks information regarding interior and exterior condition, the finding that rental properties typically are in a worse condition as compared to owner occupied properties of by Shilling et al. (1991) would support that monthly fees are higher in properties recently been converted from rentals to owner occupied as a lesser condition would require higher levels of maintenance and repair. Any influence by unmeasured property condition would therefore be most likely to underestimate the negative effect a conversion has on monthly fees.

As the data includes information about the number of apartments in a housing association, the number of apartments converted from rentals to owner occupied each year can be estimated. Figure 1 illustrates the variation in the number of converted apartments during the 20 year period of 1984 to mid-2014. The paradigm shift towards a higher priority on owned housing as compared to rentals is illustrated by the increased number of conversions from about 1999 and onwards. The subsequent years can be divided into two periods during which more than 8000 apartments were converted from rentals to owner occupied annually. Firstly during the period of 1999 to 2004, and secondly, during the period of 2007 to 
2010 after which the number of conversions decreased sharply. Given that the transaction data spans the period of 2005 to July 2014, the second of these periods can be regarded as a treatment period under which a large number of apartments are converted. The subsequent period enables for a quasi-natural experiment in which converted apartments are compared to other non-converted apartments.

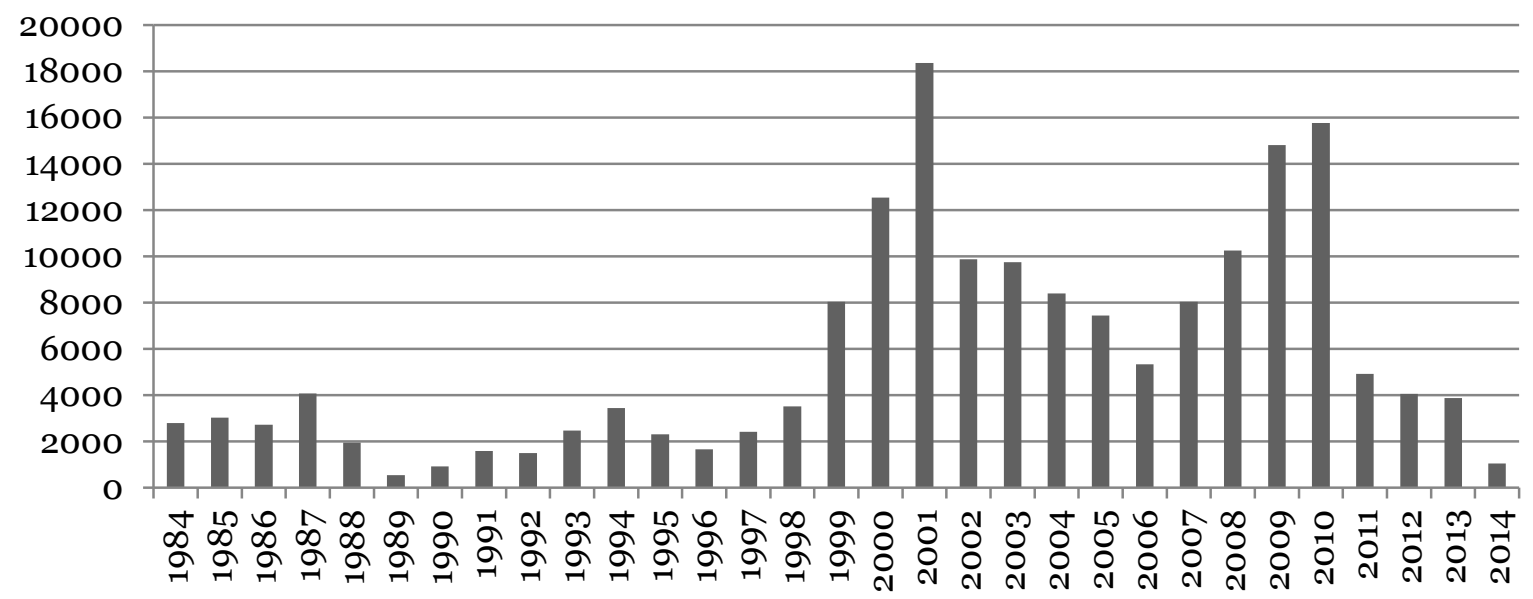

Figure 1 - Annual number of converted apartments during the period of the year 1984 to July 2014.

In order to control for apartment and property characteristics that might influence monthly fees, several models in which the natural logarithm of the monthly fee is regressed on characteristics that theoretically should influence monthly fees, in addition to a binary variable indicating a recent conversion. The Ordinary-Least-Squares model is as follows:

$$
Y=X \beta+\varepsilon
$$

Where $Y$ is a $n \times 1$ dependent variable vector with the natural logarithm of monthly fees, $\beta$ is a $n \times 1$ vector of unknown parameters associated with the explanatory variables, and $X$ is a $n \times k$ matrix of explanatory variables capturing apartment and property characteristics. The $n \times 1$ vector $\varepsilon$ consists of regression disturbances. Included variables that indicate apartment size and the number of rooms should lead to higher monthly fees. Additional variables indicating the existence of a balcony and elevator, should also increase monthly fees through maintenance costs. The finances of the housing cooperative is captured by the amount of cooperative debt associated with the apartment (which is the living area multiplied with the debt per square meter carried by the housing cooperative) which should increase monthly fees. Variables with ambiguous theoretical effect on monthly fees are property age, given that old properties are likely to 
have a higher structural quality as well as having been renovated, whilst newly constructed properties are going to have lower maintenance costs. Similarly, the number of apartments in the housing cooperative is should negatively impact monthly fees if economies of scale apply to the management of the property. A larger number of apartments do however also imply larger property complexes in which the larger contingencies are needed for property maintenance, therefore positively impacting monthly fees. Similarly, knowledge about property condition amongst board members is likely to be lower in larger cooperatives in which personal relationships between those living in the cooperative are fewer. In addition to the abovementioned control variables, binary variables indicating the month of the sale are included in order to capture the influence of time on monthly fees.

Hypotheses 1 and 2 are tested through four regression models. Firstly, a model with a binary variable indicating if an apartment was converted during the period of 2007 to 2010 is regressed on data spanning 2011 to 2012. Secondly, in order to see if the effect of a conversion on monthly fees decrease as time since the conversion passes, the same model is fitted to data spanning the period of 2013 to mid-2014. Negative coefficient estimates in both models would support the first hypothesis of lower monthly fees in conversions. A smaller coefficient estimate in the second regression as compared to an estimate based upon the previous period would support that monthly fees in conversions increase more rapidly as compared to other apartments subsequent of the conversion. When applying this measure, later conversions having taken place during the period of 2011 to 2014 are excluded. As previously mentioned, this way of estimation controls for unmeasured influences on monthly fees, as the group of conversions is kept constant.

Thirdly, a model with rolling definitions of conversions is applied. A binary variable indicating if an apartment was converted within the two years that preceded the transaction is included, as is an equivalent variable that indicates if an apartment was converted three to four years prior to the transaction. A comparison of these binary variables provides an additional way for testing the second hypothesis. 
Lastly, the second hypothesis is tested through a fourth regression in which an interaction variable that indicates the number of years having passed since the conversion for apartments having been converted during the period of 2007 to 2010. In order to support the second hypothesis, this variable should be positive. 


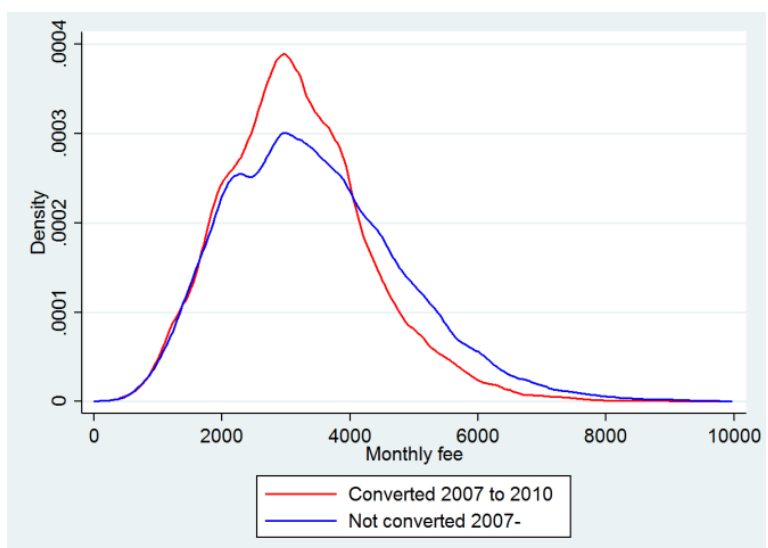

Figure 2 - Density of monthly fees during 2011 to mid-2014.

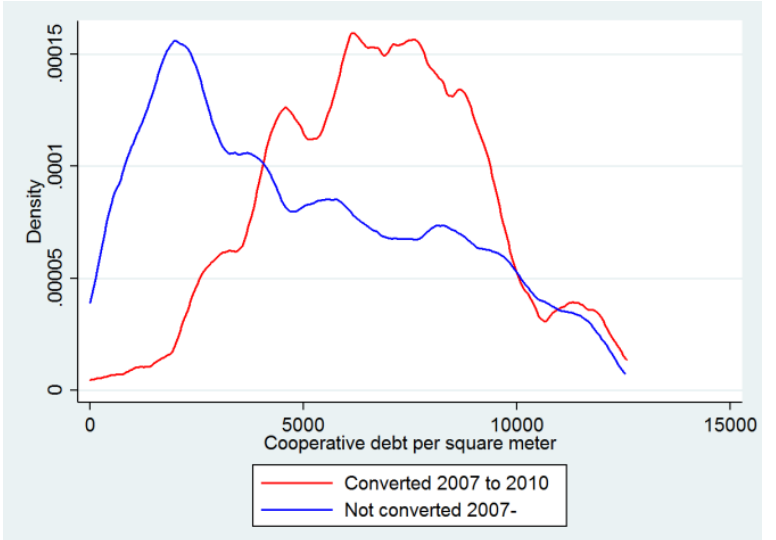

Figure 3 - Density of cooperative debt during 2011 to mid-2014.

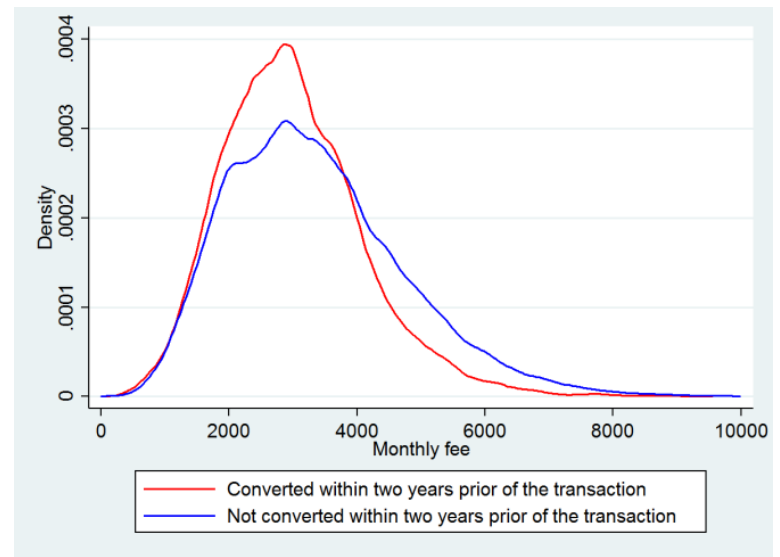

Figure 4 - Density of monthly fees during 2005 to mid-2014.

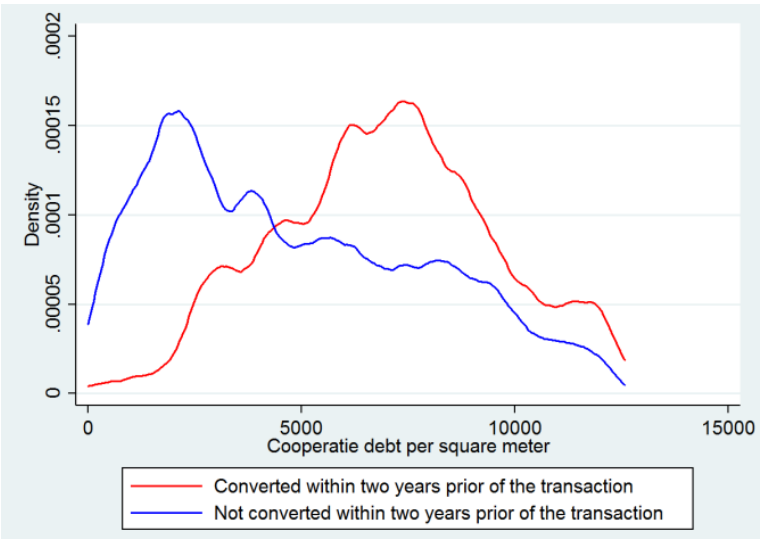

Figure 5 - Density of cooperative debt during 2005 to mid-2014. 
Before interpretation of the regression results, it should be noted that interpretation of binary variables should be done as defined as according to Halvorsen and Palmquist (1980) when the dependent variable (monthly fee) is transformed to its natural logarithm. The percentage effect on the monthly fee due to a change in a binary-variable from 0 to 1 will therefore be interpreted through the following equation: $g=100[()-1]$ where $g$ is the size of the percentage change.

As can be seen in table 2, all of the above defined regressions produce concurrent results. After controlling for apartment and property characteristics, in addition to the size and debt of the housing cooperative, apartments having been converted during 2007 to 2010 are found to have $12.1 \%$ lower monthly fees during the period of 2011 to 2012 (as seen in model 1). The alternative definition of a conversion that is applied in model 3 (converted within the two years that precede the transaction) produces an almost identical estimate of $12.1 \%$ lower monthly fees. This based upon the full sample of transactions spanning 2005 to mid-2014. These results provide strong support for the first hypothesis of lower monthly fees in recently converted apartments. The second hypothesis of a negative effect on monthly fees that decreases over time is supported by a comparison of models 1 and 2 as well as models 3 and 4. Apartments having been converted during the period of 2007 to 2010 are found to have $7.1 \%$ lower monthly fees when sold in 2013 and 2014 (model 2), as compared to 12.1\% lower monthly fees in

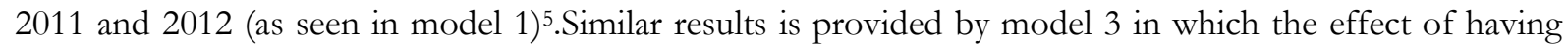
been converted three to four years prior to the transaction is found to be a $5.5 \%$ lower monthly fee, as compared to $12.1 \%$ lower monthly fees if converted within the two years that preceded the transaction.

Lastly, the second hypothesis is tested in model 4 in which the monthly fee is estimated to increase with $4.1 \%$ for each year that passes from the conversion. The model provides strong support for the second hypothesis. Noteworthy is that when controlling for years passed since the conversion, the estimated impact on monthly fee is found to be as high as $-20.7 \%$. This should be interpreted as the negative effect on monthly fee shortly after a conversion, as compared to estimates in models 1 through 3 which are smoothed over time since the conversion.

$5 \mathrm{~A}$ chow-test of difference in estimates supports that these coefficients are truly different 
Table 2 - Regression output. Dependent variable is the natural logarithm of the monthly fee.

\begin{tabular}{|c|c|c|c|c|}
\hline Variable & Model 1 & Model 2 & Model 3 & Model 4 \\
\hline Converted within 2 & & & -.1293449 & \\
\hline years & & & $(-63.82)$ & \\
\hline Converted 3 to 4 & & & -.056263 & \\
\hline years ago & & & $(-24.98)$ & \\
\hline \multirow[t]{2}{*}{ Converted 07 to 10} & -.1284836 & -.0741246 & & -.2314559 \\
\hline & $(-40.55)$ & $(-21.64)$ & & $(-10.67)$ \\
\hline Years since & & & & .0403942 \\
\hline conversion & & & & $(8.85)$ \\
\hline$*$ & & & & \\
\hline \multicolumn{5}{|l|}{ Converted 07 to 10} \\
\hline \multirow[t]{2}{*}{ Cooperative debt } & $4.05 \mathrm{e}-07$ & $4.06 \mathrm{e}-07$ & $4.11 \mathrm{e}-07$ & $5.22 \mathrm{e}-07$ \\
\hline & $(70.84)$ & $(67.58)$ & $(147.42)$ & $(18.96)$ \\
\hline \multirow[t]{2}{*}{ Living area } & .0087254 & .0086733 & .0089446 & .0079764 \\
\hline & $(78.81)$ & $(76.85)$ & $(170.50)$ & $(25.88)$ \\
\hline \multirow[t]{2}{*}{ No. of rooms } & .0458184 & .0445637 & .0437213 & .0579883 \\
\hline & $(18.17)$ & $(16.87)$ & $(36.20)$ & $(10.25)$ \\
\hline \multirow[t]{2}{*}{ Elevator } & -.0697142 & -.0878884 & -.0634111 & -.0845288 \\
\hline & $(-30.28)$ & $(-36.30)$ & $(-57.51)$ & $(-11.52)$ \\
\hline \multirow[t]{2}{*}{ Balcony } & .0335171 & .0403624 & .0380245 & .0435526 \\
\hline & $(9.91)$ & $(8.11)$ & $(22.52)$ & $(7.51)$ \\
\hline \multirow[t]{2}{*}{ Property age } & -.0028085 & -.0026691 & -.0028889 & -.0020073 \\
\hline & $(-73.88)$ & $(-67.28)$ & $(-153.00)$ & $(-9.05)$ \\
\hline No. of apartments & .0000828 & .0001195 & .0000562 & .0002116 \\
\hline in the cooperative & $(15.96)$ & $(21.80)$ & $(22.65)$ & $(3.31)$ \\
\hline Time period & $2011-2012$ & 2013-2014 & $2005-2014$ & $2011-2014$ \\
\hline No. of obs. & 42483 & 39375 & 187422 & 42366 \\
\hline $\mathrm{R}^{2}$ & 0.7201 & 0.7097 & 0.7217 & 0.6440 \\
\hline
\end{tabular}

T-values are shown in parenthesis below the coefficients. Binary variables indicating the month of transaction are suppressed from the output in order to save space. Standard errors are clustered within housing cooperatives. 
H3: Recently converted apartments will fetch a lower transactions price compared to the rest of the market.

The third hypothesis of lower transaction prices of recently converted apartment is tested through a hedonic regression model as defined by Rosen (1974). The Ordinary-Least-Squares model is as follows:

$$
Y=X \beta+\varepsilon
$$

Where $Y$ is a $n \times 1$ dependent variable vector with the natural logarithm of transaction prices, $\beta$ is a $n \times 1$ vector of unknown parameters associated with the explanatory variables, and $X$ is a $n \times k$ matrix of explanatory variables capturing apartment and property characteristics typically included in hedonic real estate models in addition to a binary variable indicating a recently converted apartment (converted within the two years that preceded the transaction). The $n \times 1$ vector $\varepsilon$ consists of regression disturbances. As seen in table 3, all variables regarding property characteristics are significant and show their expected signs. The price effect of a recent conversion is estimated to $-3.3 \%$. The third hypothesis of lower sale prices of converted apartments is therefore supported. As newly formed housing cooperatives lack financial history, this finding is concurrent with previous research having found that professional investors prefer income properties with a longer income history. It should be noted, that although highly significant, this estimate on the impact on price is fairly small and might be a consequence of unobserved differences in quality between recently converted apartments and apartments having been owner occupied for a longer time period. This hypothesis therefore deserves further attention. 
Table 3 - Regression output. Dependent variable is the natural logarithm of sale price.

\begin{tabular}{l|l}
\hline Variable & \\
\hline Converted within 2 years & -.0335874 \\
& $(-19.57)$ \\
Monthly fee & -.0000836 \\
& $(-116.47)$ \\
Living area (sqm) & .0136298 \\
& $(276.28)$ \\
No. of rooms & .050684 \\
& $(51.65)$ \\
Balcony & .0073829 \\
& $(5.53)$ \\
Elevator & .0201366 \\
& $(17.68)$ \\
Age^2 & $5.09 \mathrm{e}-07$ \\
& $(4.57)$ \\
\hline Time period & $2005-2014$ \\
\hline No. Obs. & 187430 \\
$\mathrm{R}^{2}$ & 0.9169 \\
\hline T-values are shown in parenthesis below the coefficients Binary variables indicating the postcode, binary \\
variables that indicate the month of the sale, and binary variables indicating the floor of the apartment are \\
suppressed from the output in order to save space. Standard errors are clustered within housing \\
cooperatives.
\end{tabular}




\section{Conclusions}

We have examined the paradigm shift on the Swedish property market that led to a substantial proportion of rental apartments being converted into owner-occupied units in cooperative form. This setting provides a quasi-natural experiment that test for informational asymmetries on the real estate market with strong financial incentives for those involved. We find strong support for all of our hypotheses; (1) such newly converted apartments have artificially low monthly fees, as this increases the probability of a conversion as well as increasing apartment values; (2) these levels of monthly fees are unsustainable and therefore increase more rapidly subsequent of the conversions as compared to apartments in other cooperatives, and lastly (3), a conversion will have a negative effect on sale price as buyers discount this informational asymmetry.

In sum, we provide empirical evidence of information asymmetries in the market of cooperative apartments which leads to behavior concurrent with moral hazard. These findings relate to real estate markets in general, as the findings support that informed participants will take advantage of their informational advantage if given the opportunity. Such opportunities are likely to be amplified by the cooperative form of ownership which adds complexity to the traded asset i.e. the apartment. Tenure forms in which ownership of the tangible asset is direct rather than through an additional layer such as a cooperative are therefore likely to be associated with less informational asymmetry. 


\section{References}

Akerlof, G. A. (1970). The market for" lemons": Quality uncertainty and the market mechanism. The Quarterly Journal of Economics, 488-500.

Altman, D., Cutler, D. M., \& Zeckhauser, R. J. (1998). Adverse selection and adverse retention. American economic review, 122-126.

Andersson, R., \& Turner, L. M. (2014). Segregation, gentrification, and residualisation: from public housing to market-driven housing allocation in inner city Stockholm. International Journal of Housing Policy, 14(1), 3-29.

Anglin, P. M., \& Arnott, R. (1991). Residential real estate brokerage as a principal-agent problem. The Journal of Real Estate Finance and Economics, 4(2), 99-125.

Campbell, C. M., \& Kamlani, K. S. (1997). The reasons for wage rigidity: evidence from a survey of firms. The Quarterly Journal of Economics, 759-789.

Chau, K., \& Choy, L. H. (2011). Let the buyer or seller beware: measuring lemons in the housing market under different doctrines of law governing transactions and information. Journal of Law and Economics, 54(4), S347-S365.

Chiappori, P.-A., \& Salanie, B. (2000). Testing for asymmetric information in insurance markets. Journal of Political Economy, 108(1), 56-78.

Christophers, B. (2013). A monstrous hybrid: the political economy of housing in early twenty-first century Sweden. New Political Economy, 18(6), 885-911.

Crawford, V. P., \& Sobel, J. (1982). Strategic information transmission. Econometrica: Journal of the Econometric Society, 1431-1451.

Finkelstein, A., \& Poterba, J. (2002). Selection effects in the United Kingdom individual annuities market. The Economic Journal, 112(476), 28-50.

Firoozi, F., Hollas, D., Rutherford, R., \& Thomson, T. (2006). Property assessments and information asymmetry in residential real estate. Journal of Real Estate Research, 28(3), 275-292.

Garmaise, M. J., \& Moskowitz, T. J. (2004). Confronting information asymmetries: Evidence from real estate markets. Review of Financial Studies, 17(2), 405-437. 
Geltner, D., Kluger, B. D., \& Miller, N. G. (1991). Optimal price and selling effort from the perspectives of the broker and seller. Real Estate Economics, 19(1), 1-24.

Genesove, D. (1993). Adverse selection in the wholesale used car market. Journal of Political Economy, 644665.

Greenwald, B. C. (1986). Adverse selection in the labour market. The Review of Economic Studies, 325-347.

Halvorsen, R., \& Palmquist, R. (1980). The interpretation of dummy variables in semilogarithmic equations. American economic review, 70(3), 474-475.

Handel, B. R. (2013). Adverse selection and inertia in health insurance markets: When nudging hurts. The American economic review, 103(7), 2643-2682.

Krishna, V., \& Morgan, J. (2001). A model of expertise. Quarterly Journal of Economics, 116(2), 747-775.

Kurlat, P., \& Stroebel, J. (2015). Testing for Information Asymmetries in Real Estate Markets*. Review of Financial Studies, hhv028.

Landers, R. M., Rebitzer, J. B., \& Taylor, L. J. (1996). Rat race redux: Adverse selection in the determination of work hours in law firms. The American economic review, 329-348.

Levitt, S. D., \& Syverson, C. (2008). Market distortions when agents are better informed: The value of information in real estate transactions. The Review of Economics and Statistics, 90(4), 599-611.

Levy, G. (2004). Anti-herding and strategic consultation. European Economic Review, 48(3), 503-525.

Porter, R. H., \& Sattler, P. (1999). Patterns of trade in the market for used durables: Theory and evidence: National bureau of economic research.

Rosen, S. (1974). Hedonic prices and implicit markets: product differentiation in pure competition. The journal of political economy, 34-55.

Rutherford, R. C., Springer, T., \& Yavas, A. (2005). Conflicts between principals and agents: evidence from residential brokerage. Journal of financial Economics, 76(3), 627-665.

Shilling, J. D., Sirmans, C., \& Dombrow, J. F. (1991). Measuring depreciation in single-family rental and owner-occupied housing. Journal of Housing Economics, 1(4), 368-383.

Taylor, C. R. (1995). The economics of breakdowns, checkups, and cures. Journal of Political Economy, 53-74. 